\title{
Upcycling of Technogenic Mineral Waste - Challenges and Solutions
}

\author{
Gotfrids Noviks \\ Engineering faculty \\ Rezekne Academy of Technologies \\ Rezekne,Latvia \\ Gotfrids.Noviks@rta.lv
}

\begin{abstract}
Industrial mineral waste accounts for a significant proportion of all global waste. In the European Union it is more than $71 \%(2,5 \mathrm{Gt})$ of the total amount of nonhazardous waste - construction and demolition waste, ash and slag, tailings residues, unconditioned waste rocks, etc. In Latvia, the share of this waste is about $20 \%$. Due to the fact that they are inert, non-biodegradable materials and cannot be used for energy production and cannot be reduced by incineration, their stocks are increasing every year. Their utilization volumes are low and focused mainly on use as backfill when carrying out various earthworks.

At the same time, mineral waste, both in terms of composition and structure, physical and chemical properties, is a serious mineral resource, the processing of which can result in high-quality useful products, thus implementing the waste upcycling principle - the newly acquired product has higher added value than the original.

The paper evaluates the physical and technical possibilities and perspectives for the production of eco-innovative materials from mineral waste - geopolymers, glass ceramics, porous ceramics and mineral-organic composite materials.

Keywords - technogenic mineral waste, upcycling principle, geopolymers, composites
\end{abstract}

\section{INTRODUCTION}

The amount of any mineral resource in nature is objectively limited and gradually diminishes.

The stable supply of mineral resources to the industrial sector is one of the most important problems for the sustainable development of humankind.

There are different ways of possible solutions to this problem - they can be both extensive and intensive.

Among the extensive ones can be noted the following:

1. Discovery of new mineral deposits - expansion of geological exploration in hitherto little-explored areas and depths.
2. Discovering and / or intensifying the use of new mineral resources (not from the depths of the Earth - e.g. minerals from seawater, magma, space objects).

The intensive directions are:

1. Development of extraction methods for very low concentrations of the useful component in minerals, thus involving the use of ores listed so far as waste rocks, or the waste rock dumps of already developed deposits, where the content of the useful component is lower than possible for extraction at the moment.

2. Replacement of the critical mineral resource required for production with other minerals, the amount of which is much larger or even unlimited - finding alternatives to them. As we know, the Earth's crust consists mainly of silicates - the use of silicon and its compounds and the substitution of other substances with them in the sphere of production and consumption could become a radical solution to the problem of depletion of mineral resources. 3. Reuse of used mineral resources as technological resources - secondary raw materials in the sphere of production and consumption.

The extraction, processing and exploitation of mineral resources generate a lot of residue and waste, the volumes of which increase over time.

Analyzing the composition, structure and properties of this waste, it can be seen that they are essentially the same mineral formations as natural minerals and rocks. Mineral waste can be considered as a transformed primary mineral resource into another category of secondary (technogenic) mineral resources.

Many mineral wastes have retained virtually unchanged the components from which the original product was formed, as well as partially the original structure and physical properties, and can therefore potentially be used either directly or after processing to serve as a raw material 
for new products - thereby reducing the intensity of the depletion of non-renewable resources and the amount of waste going to landfill.

Over the last 40 years, the world's consumption of mineral resources has increased 25 times, but the amount of industrial waste generated is 10-100 times higher. Therefore, saving resources and reducing pollution is in fact one and the same integral problem and must be tackled in a complex way.

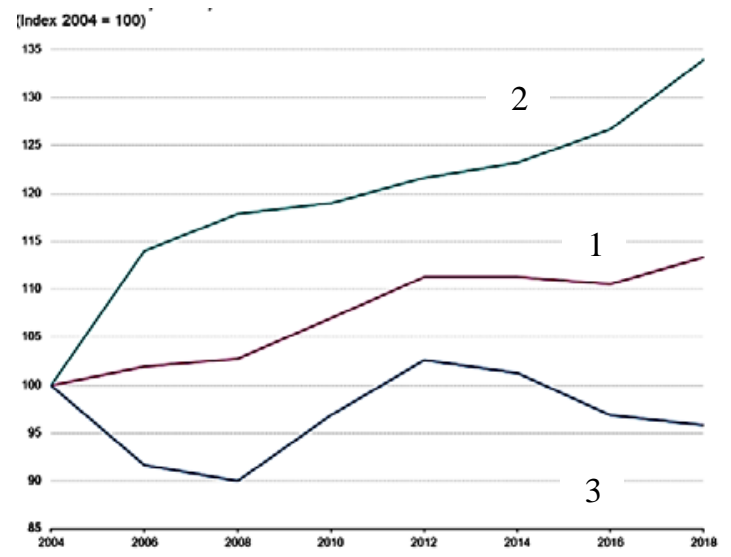

Fig.1. Changes in the amount of waste produced (1), recovered (2) and deposited(3) since 2004in the 28 countries of the

European Union (Eurostat (online data code: env_wasgen)

At the same time, although the level of mineral waste processing has been increasing over the last 15 years (Fig. 1 ), its use is not related to the production of new highquality products. Statistics show that the treatment of waste currently produced in the European Union is mainly related to its disposal (46\%). Waste recycling (which actually can be considered as their using as technogenic resources) are subjected to $873 \mathrm{Mt}$ of waste, which constitutes $38 \%$ of the processed waste.

\section{MATERIALS AND METHODS.}

In this work, based on our previous research from the 1990s on the complex and rational use and processing of mineral and technogenic resources [1],[2],[3],[,[4],[5] as well as on the analysis, compilation and calculation of literature data provides a methodology for evaluating and substantiating the prospects for the processing of technogenic mineral materials. The main thesis on which this methodology is based is the concept of up cycling. Waste recycling should focus on the development of recycling technologies that use end products with a quality not lower than the quality of the original product - the principle of "up-cycling" is now a predominant practice instead of the principle of "down-cycling", where each subsequent recycling phase produces product of a quality lower than the previous [6],[7].The development of an eco-innovative product from secondary resources (waste) with better (at least not inferior) properties than the properties of the former product requires detailed and comprehensive investigation of physical, chemical, structural properties of these raw materials and processes in different physical fields.

Life cycle analysis of the global extraction and production of seven metals (iron, aluminum, copper, zinc, lead, nickel and manganese) shows a strong impact of these processes on the quality of the environment. It is expected that the impact of the use of these seven metals on the environment in 2060 will increase from two to four times compared to 2011.

The extraction and production of cement raw materials, sand and gravel have a much lower specific impact (per kilogram of production) on the environment, but their use is so large that the total impact also increases. Together, seven metals and two building materials account for almost a quarter of all greenhouse gas (GHG) emissions and one sixth of total energy demand.

Although the recycling and use of secondary materials cannot be without an impact on the environment, it is generally ten times lower than the impact of primary production processes.

\section{III.RESULTS AND DISCUSSION}

The European Commission (EC) approved the European Waste Catalog (EWC) by Decision 2000/532 / EC [8]. The EWC is a hierarchical list in which all waste is divided into twenty main sections, each assigned a two-digit code from 01 to 20. Most sections are based on industry, but some are based on materials and processes. Each waste is assigned a six-digit code in each compartment.

We propose a waste classification based on the European Waste Catalog but more appropriate for the research and analysis of treatment processes of technogenic materials (Fig. 2).

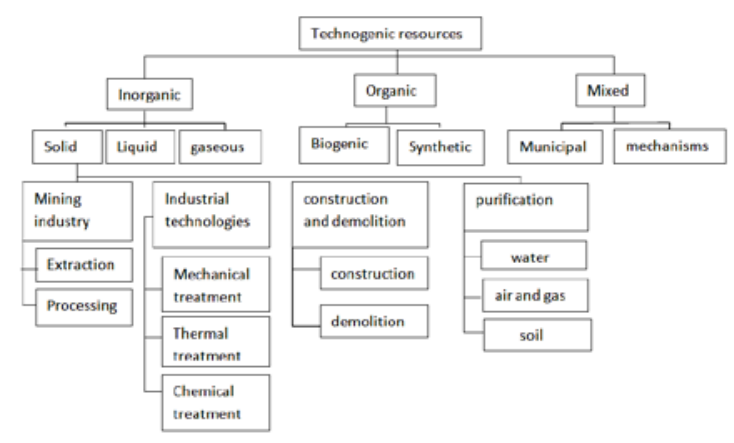

Fig 2. Classification of technogenic waste sources . Detailed group of inorganic solid technogenic resources

The recycling of mineral waste is in fact a process in which the physical and chemical properties of a technogenic resource are transformed into the properties of the intended end product. Therefore, it is logical to divide all properties into three groups according to the analyzed process:

- properties that characterize the raw material;

-characteristics that characterize the final product; -properties that describe the ability of the raw material to transform into the final product - physical and chemical activity of the raw material.

It is known that the physicochemical activity (reactivity) of a thermodynamic system is characterized by the speed and depth of the process. The direction and depth of the process are determined by thermodynamic laws, but the speed of the process - by the kinetics. 
The change of the Gibbs energy G of system can be taken as the main thermodynamic parameter what regulate efficiency of raw materials transformations.

$$
\Delta G=\Delta H-T \Delta S
$$

The process rate constant $K_{V}$ can be taken as a kinetic parameter of the system.

$$
K_{V}=d \xi / d t\left[V_{1}^{a 1} \cdot V_{2}^{a 2} \cdots V_{n}^{a n}\right]^{-1}
$$

where $\mathrm{d} \xi$ - the degree of perfection of the process during the period dt, $V_{(1,2,3, \ldots)}$ - relative volumes of the components included in the interaction, $\mathrm{a}_{(1,2,3, \ldots)}$ empirical indicators of the nature of the interaction process.

It is known, that the higher the negative value of $\Delta \mathrm{G}$ and the higher the positive value of $K_{V}$, the more active the process will be. Therefore, the process activity parameter can be evaluated by the complex parameter $\alpha$, which is the product of these two indicators.

$$
\alpha=-\Delta G \cdot K_{V}
$$

In turn, the Arrhenius equation determines the dependence of $\mathrm{K}_{\mathrm{V}}$ on the activation energy $\mathrm{E}_{\mathrm{a}}$

$$
K_{V}=A \cdot \exp \left(-E_{a} / R T\right)
$$

Hence

$$
\alpha=(T \Delta S-\Delta H) A \cdot e^{(-E a / R T)}(5)
$$

In the case of chemical reactions, these parameters are within the following values: $A=1010-1014 \mathrm{~s}^{-1}, \mathrm{E}_{\mathrm{a}}=50$ $300 \mathrm{~kJ} / \mathrm{mol}, \Delta \mathrm{S}=10-500 \mathrm{~J} / \mathrm{mol}, \Delta \mathrm{H}=300-5000 \mathrm{~kJ} /$ mol.

Using these regularities, it is possible to perform a comparative analysis of any chosen type of interaction of mineral components and, consequently, to substantiate the usefulness and efficiency of its implementation from the physicochemical point of view.

Analyzing the results of research on the dependence of mineral properties on the effects of external fields, the following can be concluded:

1. In the general case, changes in the physical parameters of a mineral occur in a non-monotonic manner. This manifests in the extremes of correlation curves, changes in the speed of processes at different levels of exposure. Thus, the strength of a number of rocks (marble, gabbros, labradorite, etc.) decreases with increasing temperature, while for others the strength increases (urtite), but quartzite, granite have a maximum strength in the respective temperature range. The parameters of elasticity also change analogously. In addition, it is important which physical fields cause the temperature to increase in the mineral. Heating of iron quartzite with a high-frequency electromagnetic field gives a minimum of strength. These facts show that changes in physical parameters occur in the process of realization of several mechanisms of interaction between matter and field, the effects of which are different and sometimes even opposite.

2. Different modes of exposure cause different changes in physical parameters. In addition, depending on the composition and structure of the substance, the same mode of action may cause different changes in the physical parameters of the mineral.

3. Changes in the physical parameters of the minerals as a result of exposure to external fields after removal of the acting field may be permanent, may increase, or may relax over time completely or partially (Fig.3). These changes are the means by which it is possible to transform a mineral into a useful product, to change its properties in the desired direction. Thus, previously exposed minerals containing quartz up to $500^{\circ} \mathrm{C}$ are much easier to grind in crushers and mills, grinding energy intensity is reduced by $30-40 \%$. On the other hand, rocks characterized by an increase in plasticity with temperature (e.g. gabbros) after heating increase the energy intensity of crushing. Preheating of materials containing metallic minerals in a high-frequency electromagnetic field cause cracking in the grain contact areas, resulting in crushing to give a crushed material from which the metal-containing fractions can be efficiently separated.

On the other hand, in the fields of ionizing flows the processing results gradually relax and disappear. The same happens with mechanical activation in high-intensity dynamic fields. This means that the time of use of the induced changes in minerals is limited, which must be considered in the implementation of technological processes.
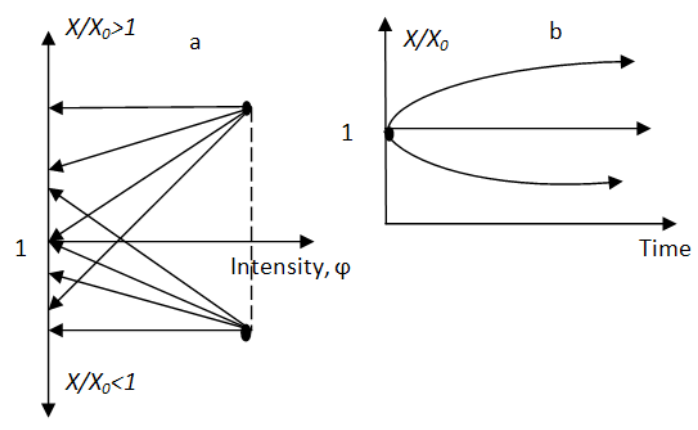

Fig.3. Possible changes in the effect after the exposure to the physical field depending on the field strength (a) and the time after exposure (b). $\mathrm{X} / \mathrm{X}_{0}$ - the ratio of the value of the current physical parameter $\mathrm{X}$ to the initial mineral parameter $\mathrm{X}_{0}$ ( $\mathrm{a}$ - before exposure, b-obtained as a result of exposure).

4. The result of exposure of physical fields to minerals depends on the time, intensity of the field exposure and the rate of its change, cyclicality and other parameters characterizing the physical treatment regimes.

Compliance with the upcycling principle for the conversion of mineral waste into high quality products can be assessed according to the following criteria:

1. The product is obtained from low-value raw materials which are currently not used at all or little and only as an auxiliary material.

2. The parameters of the obtained product, which characterize the quality of its use, are at the level of the existing product or exceed it - the new product can be used as an alternative.

3. The fields of application and range of the new product become wider compared to the traditional product.

4. The technology of manufacturing the new product does not generate or generate much less waste (especially hazardous), does not cause pollution, does not increase the negative burden on the ecological environment.

5 . The production of the new product from mineral waste is economically advantageous - at least does not exceed or insignificantly exceeds (in the first stage of 
implementation) the economic costs of production of the traditional product.

These criteria can be normalized and quantified by taking the relevant parameters of the traditional product as a basis and applying them to the parameters of the alternative product.

Thus, coefficients can be obtained:

Raw material value factor $\mathrm{V}$

$$
V=\frac{\text { mineral waste price }}{\text { traditional raw material price. }}
$$

Quality factor of the manufactured product Q

$$
Q=\frac{\text { quality of the alternative product }}{\text { quality of the traditional product }}
$$

Ecological impact factor D

$D=\frac{\text { impact of the production of the alternative product }}{\text { impact of the production of the traditional product }}$

Area of use factor $\mathrm{J}$

$$
J=\frac{\text { uses of the alternative product }}{\text { uses of the traditional product. }}
$$

Economic expenditure ratio $\mathrm{E}$

$$
E=\frac{\text { production cost of the alternative product }}{\text { production cost of the traditional product. }}
$$

Based on these factors, the level of upcycling can be quantified by the complex indicator UC

$$
U C=\frac{Q . J}{V \cdot E . D}
$$

The ideal option is when Q, $\mathrm{J}>1$, but $\mathrm{V}, \mathrm{E}, \mathrm{D}<1$. When comparing the possible processing options, the one with the highest parameter UC is preferred.

The analysis shows that these criteria for obtaining quality products from mineral waste at the moment are most met by such promising directions of construction and building materials production as the development of binders, porous and glass ceramics, geopolymers and composite materials (including organominerals).

The main physical processes used in the development of these technologies are machining-disintegration (crushing and grinding), integration (consolidation, dynamic and static pressure); heat treatment - integration (sintering, melting, solid phase reactions), disintegration (chemical reagent environment, biogeochemical processes).

The use of additional physical effects - mechanical, thermal, chemical activation of substances, acoustic (especially in the ultrasonic range) and electromagnetic (especially, high frequency range) fields, phase and polymorphic effects - has a perspective for the intensification of basic processes in technology.

Thus, the areas of research and information base of mineral properties and their changes are specified: composition - both mineral and chemical;structure - macro and crystalline scale; properties - mechanical, thermal, physico-chemical - their changes, stability and critical (extreme) values under the influence of physical fields.

HIgher level of mineral waste processing technologies are associated with their physico-chemical, chemical and physico-biological disintegration. Research in these areas for mineral waste is currently limited, but mining industry uses hydrometallurgy, geobiotechnology, oxidation and reduction reactions to extract useful chemical elements or compounds from unconditioned ores and residues.

All types of mineral waste processing, except when the mineral waste is used directly or with little mechanical pre-treatment can be grouped in two opposite directions disintegration and integration. Under the term "disintegration" we combine a wide group of physical, physic-chemical and chemical processes in which a mineral is broken down into components of various scales - from mineral aggregates to individual chemical elements (Fig. 4). The efficiency of physical field-substance interaction processes highly depends on the free surface area of the exposed mineral, surface energy, crystal lattice defects, their types and concentration, structural distortions, diffusion and reactivity. All these parameters increase strongly after crushing the mineral, in proportion to the degree of crushing. Therefore, all processing activities start from the crushing and grinding of the material. Disintegration, by its nature and types of processes, is sharply divided into three directions mechanical, physicochemical and microbiological.

The goals of disintegration are:

- crushing of mineral material to the stage necessary for its further use in a direct way or for activation of further processing (including the implementation of the next disintegration and also for the provision of consolidation processes);

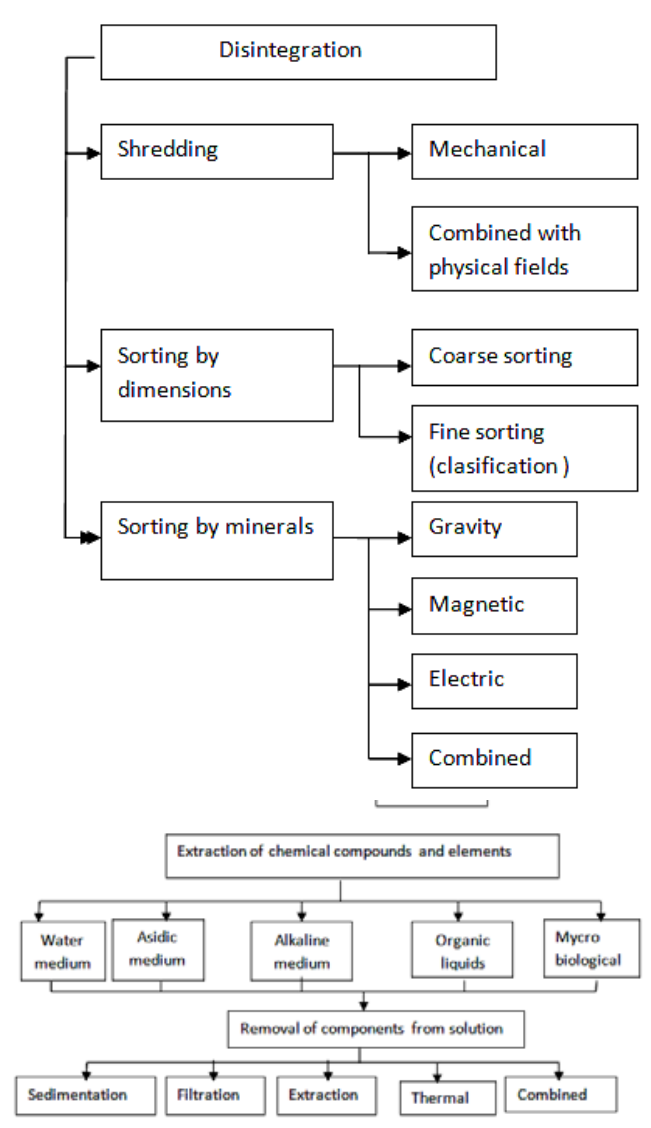

Fig.4. Classification of disintegration methods.

•sizing of crushed mineral material (sifting, classification);

-division by composition (mineral individuals);

•extraction of the single compounds or chemical elements As shredding is energy-intensive - in many cases exceeding $40 \%$ of the total energy consumed in recycling - it becomes very important to maximize the recycling of mineral waste already shredded in the basic technology or generated at the relevant stages of this technology - ash, 
treatment plant dust, enrichment plant tails, since in this case the crushing stage becomes redundant. In other cases, it is necessary.

By "integration" we mean the direct compaction of a loose aggregate - consolidation to form a solid monolith, as well as the combination of individual components through binders, thermal and other field effects or chemical reactions, resulting in a compact new substance with new properties. The task of integration (consolidation) is to create strong mechanical bonds between individual grains, crystals or their elements of a mineral or a mixture thereof. The integration of minerals is performed with crushed, often highly dispersed materials, except in cases when large pieces of raw material (slabs, blocks) are combined in a cohesive macrostructure. So, the first stage of integration (consolidation, monolithization) technology also starts from disintegration. The choice of the next processing stage is related to the production of the planned final product and the properties that need to be created in the obtained product. There are two options - to move the crushed mineral for further direct processing without any additives or to add additional components and create a batch of the respective composition.

In the basic processing process, the crushed material or their respective mixture is exposed to physical or substance fields (solutions).Considering the currently most feasible and effective types of exposure to minerals, we distinguish four types of exposure - the effects of mechanical, thermal, chemical reagents on the environment and complex (combined) fields (Fig. 5). Each of these routes of exposure is subdivided according to the physic-chemical process that makes up the structure and composition of the final material.

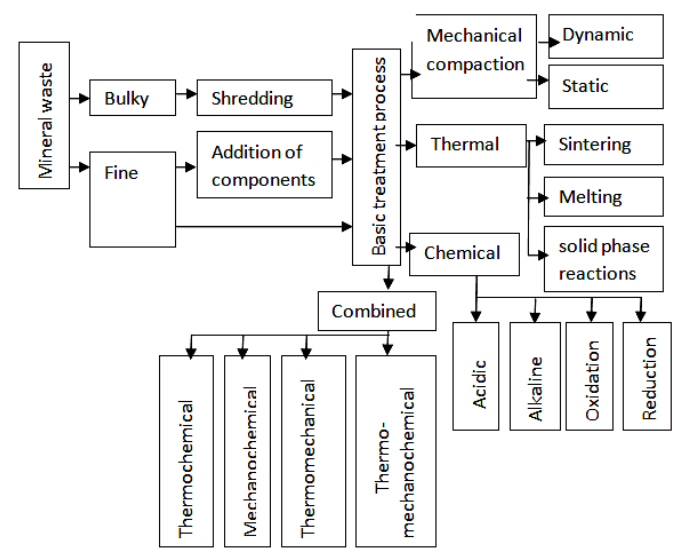

Fig.5. Classification of integration methods.

Depending on the types of fields acting, their intensities, duration of action and modes, new different types of energy bonds between the particles of the material change or are formed, both interatomic (covalent, ionic) and intermolecular (electrostatic, donor-acceptor, hydrogen). In the sintering process of materials at temperatures of $1000^{\circ} \mathrm{C}$ and more, traditional ceramics are formed crystalline inorganic, non-metallic material, consisting mainly of oxides, nitrides or carbides. A mixture of lowmelting clay minerals with quartz sand is used as a raw material in traditional brick production technology.
Glass is the result of the melting of minerals and forms a separate group of amorphous solids.

In the appropriate technological process, an intermediate product can be obtained - glass ceramics, which is used for the production of tiles and other construction materials. Many technogenic mineral wastes can be included in the production of glass ceramics. This issue has received a great deal of attention recently [9], [10]. Glass-ceramic technology includes a two-stage heat treatment process nucleation (sludge formation) and crystallization stages. The glass-ceramic structure is characterized by fine, chaotically oriented crystals embedded in a matrix of partially amorphous material, without pores, micro cracks and voids.

A study [11] has shown that basalt and residues from the ceramics industry can be used in the production of glass ceramics. The chemical composition of the used raw materials is quite close to most of the technogenic minerals, including the composition of construction debris (clay and silicate bricks, concrete residues).

The obtained glass-ceramics showed high mechanical properties - hardness from 9.6 to $10 \mathrm{GPa}$, bending strength in the range from 92 to $135 \mathrm{MPa}$ (Fig. 6), water adsorption at zero level. As a result of sintering, four mineral phases were formed - grown, anortitis, olivine and magnetite. Typically, the addition of ceramic waste to basalt increased the mechanical properties of glass ceramics by up to $40 \%$ compared to ceramics made from basalt alone. This leads to the conclusion that the use of this waste in the production of glass-ceramics can prove to be quite efficient.

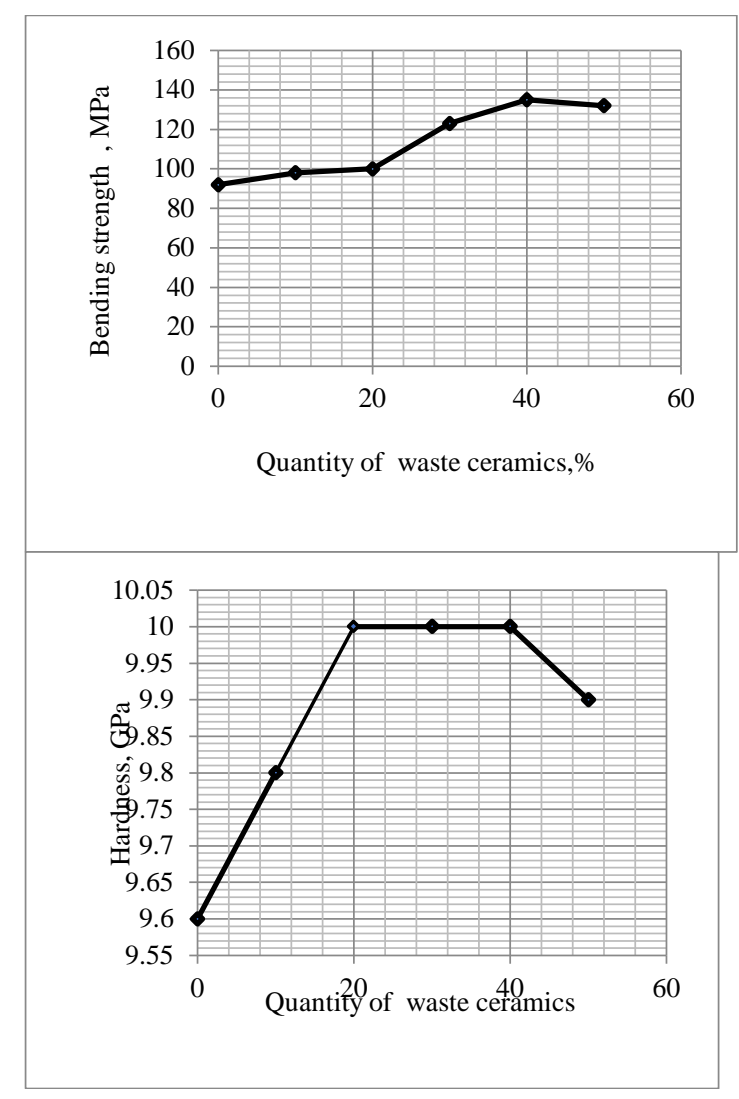

Fig.6. Changes in glass ceramic mechanical properties with addition ceramic waste. 
In [12], fly ash and tails of a rare metal ore from the Baijan Obo enrichment plant in China were studied as a raw material for the production of glass ceramics.

The mineral waste from the enrichment plant was added to the ash in various proportions from 10 to $50 \%$ by weight. The results showed that the density of the obtained glass-ceramics is about $3 \mathrm{~g} / \mathrm{cm}^{3}$, bending strength about $193 \mathrm{MPa}$, hardness (according to Vickers method) 1.3 $\mathrm{GPa}$, thermal expansion coefficient $-8.3 .10^{-4} \mathrm{~K}^{-1}$.

Another study [13] examined the use of enrichment plant residues for the production of porous glass ceramics. The mixture was formed from operational waste from boron mineral deposits, basalt, ordinary soda-lime glass production residues, silicon sand and limestone.

The prospect of inorganic waste recycling is the use of inorganic polymer technologies. As is known, inorganic polymers are, for the most part, products of the synthesis of chemical elements of groups III-VI.

Artificially synthesized inorganic polymers are currently widely used. French chemist J.Davidovits [14] discovered that the reaction of metakaolin and soluble alkali silicate formed a binder capable to replace cement. Subsequent studies have shown that there are two possible directions of polymerization: in alkaline media $(\mathrm{Na}+, \mathrm{K}+, \mathrm{Li}+$, Ca ++ , Cs + and others) and in acidic media (phosphoric acid, organic carboxylic acids). The alkali method is currently being further studied. J.Davidovits called such materials geopolymers (other names - alkali-activated cement, alkali-activated binder, alkaline cement, and alkaline binder.

Geopolymer, - inorganic binder (aluminosilicon gel) with low calcium content, consisting of tetrahedral $\mathrm{SiO}_{4}$ and $\mathrm{AlO}_{4}$ stages, polycondensed in the spatial structure as a result of reaction between aluminosilicates and alkaline activators [15]. Alkali activation usually occurs by mixing powdered aluminosilicate with liquid activator sodium or potassium hydroxide at most temperatures up to $100^{\circ} \mathrm{C}$. The main products of the interaction between aluminosilicate and alkali are of two types. One of them is an aluminum silicate gel consisting of alkali and alkaline earth hydroalosinosilicates (R-A-S-H). The second type is low basic hydro silicates, calcium hydro aluminates (C-S$\mathrm{H}, \mathrm{C}-\mathrm{A}-\mathrm{H}$ ). The hardening of the gel results in waterresistant hydrates - hard artificial stone with high mechanical properties and chemical stability. The composition of geopolymers is characterized by a formula $\mathrm{Mn}$ [- (Si-O) zAl-O] $\mathrm{n} \cdot \mathrm{wH}_{2} \mathrm{O}$, wherein $\mathrm{M}$ is $\mathrm{K}, \mathrm{Na}$ or $\mathrm{Ca}$, $\mathrm{n}$ is the degree of polycondensation, $\mathrm{z}$ is $1,2,3$ or more. The Si: Al ratio is crucial in shaping the properties of the geopolymer - as the $\mathrm{Si}-\mathrm{Al}$ ratio increases, the heat resistance and mechanical strength of the geopolymer increase. Geopolymers have good chemical and thermal stability, high compressive strength and low permeability. In addition, the production of geopolymers is cheaper and less energy-intensive and more environmentally friendly (emitting $80 \%$ less $\mathrm{CO}_{2}$ ) compared to the production of Portland cement. Metakaolin is the most widely used raw material in the production of geopolymers because of its high reactivity and ability to form homogeneous reaction products. Studies have shown that a variety of natural and technogenic mineral raw materials in the composition of which are aluminum silicates can be used in the production of geopolymers. The main criterion for the suitability of raw materials is the degree of disordered structure of the aluminosilicate substance. Many silicaand alumina-rich minerals (ash , slag, granite waste, clay minerals in the original and calcined state, effluent rocks with a high degree of vitrification, construction debris, etc.) may be used in geopolymers production.

The report [16] informs about experiments where geopolymer was produced of unconditioned kaolin residues containing about $59 \% \mathrm{SiO}_{2}, 33 \% \mathrm{Al}_{2} \mathrm{O}_{3}, 3 \%$ $\mathrm{Fe}_{2} \mathrm{O}_{3}, 2 \% \mathrm{TiO}_{2}$.

Mineral wastes such as fly ash and glass fragments are also subject to geopolymerization. In [17] it was shown that the polymerization of inorganic materials can be used not for the final product, but for the production of an intermediate-gel, which is further subjected to heat treatment - ceramication. The mixture of fly ash and glass waste was activated in weakly alkaline solutions, resulting in a polymerized gel suspension which is mechanically foamed by the addition of surfactants, dried and sintered without foam structure collapse at temperatures below $1000{ }^{0} \mathrm{C}$ to form a highly porous, chemically stable, mechanically durable glass ceramics.

The report [18] analyzes two possibilities of chemically bound ceramics extraction by processing mine waste: by alkali activation (geopolymerization) and acid activation (chemically bound phosphate ceramics). It was found that the activation of alkali has been studied for 28 silicate minerals, and results have been obtained confirming the efficiency of this method in the production of ceramics.

Alkali activation is a promising technology for the recycling of inorganic waste and industrial residues in construction materials. This process makes it possible to regulate the properties of the final product according to the chemical composition of the raw materials. At the same time, it is less sensitive to various non-essential impurities. Studies have been carried out at the Kazan State University of Architecture and Construction in which finely dispersed mineral materials have been subjected to alkali treatment: quartz sand, processed foundry sand,, ash, ceramic brick and Portland cement concrete fragments, synthetic zeolite waste. As a result of slag use studies, it has been found that the highest mechanical properties are achieved after grinding the batch to a degree of fineness that gives a mixture with a degree of dispersion (specific surface area) of $600-700 \mathrm{~m}^{2} / \mathrm{kg}$. The inclusion of $30 \%$ crushed ceramic bricks in the mixture increases the stone strength of the geopolymer by $30 \%$ (for example, a geopolymer made of neutral slag with silicate coating increases the strength from $116 \mathrm{MPa}$ to $140 \mathrm{MPa}$, but with soda ash increases from 61 to $80 \mathrm{MPa}) .25-30 \%$ ash additive for slag with a dispersion of $500-800 \mathrm{~m}^{2} / \mathrm{kg}$ increases the strength of geopolymer stone up to $60 \%$ during heat treatment. Micro silicon with a specific surface area of $15,000 \mathrm{~m}^{2} / \mathrm{kg}$ additive in the amount of 5$7 \%$ gives maximum strength values.

When the mineral waste is intended to use for production materials, which are the replacement of an existing traditionally used product, its component or as an intermediate product, the research program should consist of the following stages (Fig.7): 


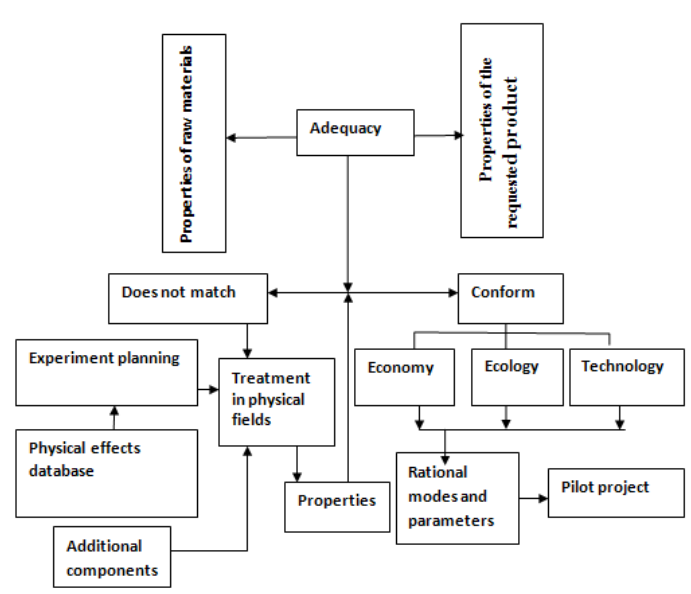

Fig.7. Algorithm for selection of research on the substantiation of mineral waste processing technologies

$>$ the basic requirements and properties $(\mathrm{P})$ that the product must meet are precisely defined the final product; $>$ mineral properties are studied (M);

$>$ the correspondence of these properties is determined (M $\sim \mathrm{P}$ );

$>$ in the event of non-compliance, specify the exact parameters of the non-compliance and, on the basis of a database of physical effects, assess the possible courses of action that could lead to the required property;

$>$ organizes the planning of experiments and performs experiments;

> investigates the properties $\mathrm{M}$ 'of the material obtained during the experiments and their compliance with the requirements ( $\mathrm{M}$ ' P);

$>$ if necessary, continue experiments with other physical fields.

\section{CONCLUSIONS}

Development of high-quality up cycled products from mineral waste is one of the perspective directions, which on the one hand ensures saving of natural mineral resources and on the other hand reduction of environmental pollution by implementing the principles of circular economy.

There may be important economic and environmental benefits of using inorganic mineral waste for producing new up cycled products. For example , Australian researches Ross P.Williams and others [19] estimated, that producing geopolimers from waste raw materials it is possible to achieve 44-64\% improvement in greenhouse gas emissions over ordinary Portland cement production , while the financial cost of geopolymers are $7 \%$ lower to 39\% higher compared with OPC.

In recent years, many studies [20],[21],[22],23],[24],[25],[26],[27] have been carried out in the world which have proven that the processing of mineral waste in accordance with the current economic and environmental conditions is the most reliable in the production of building materials such as cement, various classes of ceramics (light bricks, water permeable bricks, tiles, glass ceramics), geopolymers, mineral-organic composites.
The successful development of these recycling technologies requires the acquisition of much broader and deeper information on the properties, composition, structure and ability of mineral waste to change them in the required direction as a result of exposure to external physical and chemical fields.

An appropriate classification of technogenic mineral resources for processing in this direction has been developed, thermodynamic parameters characterizing the efficiency of impact on the mineral environment have been determined, criteria for evaluation of processing technology in accordance with the upcycling principle have been proposed.

The classification of mineral waste disintegration and integration processes is given. An optimal algorithm for evaluation and research of possible physical processes of mineral waste processing is proposed.

\section{REFERENCIES}

[1] Г.Я.Новик, С.В.Ржевская. ”Физико-техническое обеспечение горного производства”, М.Недра, $1995,258 \mathrm{c}$.

[2] Г.Я.Новик, М.Г.Зильбершмидт.“ Управление свойствами горных пород в процессах горногопроизводства”, М. Изд.ЛКИ, 2010, 224c.

[3] G.Noviks. "The development of complex analysis system of ecotechnology paramaters“, Rēzeknes augstskolas zinātniskie raksti”, 2003, pp.97-110

[4] G.Noviks.”Basis of optimal mineral inorganic waste processing methods”, Environment. Technology. Resources. Proceedings of the 6-th International Scientific and Practical Conference, 2007, Rezekne, pp.87-101

[5] G.Noviks. "Physico-technical approach to design of composites from mineral and polymer technogenic resources”, Environment. Technology. Resources. Proceedings of the 10-th International Scientific and Practical Conference, 2015, pp162-169,

[6] Sung, K.; Cooper, T.; Kettley, S. "Individual Upcycling Practice: Exploring the Possible Determinants of Upcycling Based on a Literature Review”, Sustainable Innovation Conference, Copenhagen,2014.

[7] G.Noviks,'Eco-innovative solutions for the processing of technogenic mineral resources Environment. Technology. Resources. Proceedings of the12-th International Scientific and Practical Conference, 2019, Rezekne, pp. 204-209

[8] European Waste Classification for Statistics, version 4 Commission Regulation (EU) No 849/2010 of 27 September 2010 amending Regulation (EC) No 2150/2002 of the European Parliament and of the Council on waste statistics

[9] F.L.da Silva, F.G.S.Araújo, M.P.Teixeira, R.C.Gomes, F.L.vonKrüger, "Study of the recovery and recycling of tailings from the concentration of iron ore for the production of ceramic", Ceramics International 40,2014,pp.16085-16089

[10] A.Jonker, J.H. Potgieter, "An evaluation of selected waste resources fertilization in ceramic materials application”, Journal of the European Ceramic Society 25 , 2005,pp.3145-3149.

[11] G.A. Khater, A. Abdel-Motelib , A.W. El Manawi , M.O. Abu Safiah"Glass-ceramics materials from basaltic rocks and some industrial waste”, Journal of Non-Crystalline Solids, 358 , 2012, pp. 1128-1134

[12] LiBaowei, Deng Leibo, Zhang Xuefeng, Jia Xiaolin, "Structure and performance of glass-ceramics obtained by Bayan Obo tailing and fly ash” Journal of Non-Crystalline Solids, 380, 2013, pp. 103-108

[13] Mauro Marangoni, Enrico Bernardo, Suna Cetin, ”Lightweight glass-ceramic tiles from the sintering of mining tailings", Ceramics International, 41, 2015, pp.5294-5300

[14] Davidovits, J. Geopolymers. Journal of Thermal Analysis 37, 1991, pp.1633-1656 
[15] PaivoKinnunen, Arnold, Ismailov, Soili Solismaa, Harisankar Sreenivasan, Marja- Liisa Raisanen, Erkki Levanen, ,Mirja Illikainen, "Recycling mine tailings in chemically bonded ceramics. A review", Journal of Cleaner Production, 174, 2018, pp.634-649

[16] Marlon A. Longhi, Erich D. Rodríguez, Susan A. Bernal , John L. Provis ,Ana Paula Kirchheim,” Valorisation of a kaolin mining waste for the production of geopolymers", Journal of Cleaner Production, 115 ,2016, pp.265-272

[17] Acacio Rincón Romero, Daniele Desideri, Aldo R. Boccaccini, Enrico Bernardo,"Up-Cycling of Iron-Rich Inorganic Waste in Functional Glass-Ceramics”, Minerals 2020, 10, 959; doi:10.3390/min10110959

[18] Paivo Kinnunen, Arnold Ismailov, „Soili Solismaa , Harisankar Sreenivasan, MarjaLiisa Raisanen, Erkki Levanen, Mirja Illikainen, "Recycling mine tailings in chemically bonded cerami cs.A review", Journal of Cleaner Production, Vol. 174, 2018,pp. 634-649

[19] Ross P.Williams, JanineLay, Arievan Riessen, Glen D.Corder."Costs and carbon emissions for geopolymer pastes in comparison to ordinary portland cement", Journal of Cleaner Production,Vol.19, Iss. 9-10, 2011, pp. 1080-1090

[20] Natalia Babak1.Emperor Alexander, "Structure of Atoms of the Main Phase of Industrial Wastes Predict Properties of Building Materials in Transport Construction in Cold Regions", St. Petersburg State Transport University, Proceedings of TRANSOILCOLD, Transportation Soil Engineering in Cold Regions, Volume 2.2019.
[21] Hailing Kong, Zhanqing Chen, Luzhen Wang, Haide Shen "Experimental study on permeability of crushed gangues during compaction,” International Journal of Mineral Processing 124 2013, pp. 95-101

[22] Qianxing Huang, Taoyong Liu , Jiashuo Zhang, Xi He, Jianlei Liu, ZhiweiLuo, AnxianLu,"Properties and pore-forming mechanism of silica sand tailing-steel slag-coal gangue based permeable ceramics”,School of Materials Science and Engineering, Centra South University, Changsha 410083, China. Construction and Building Materials 253, 2020, 118870.

[23] Sung-Hoon Kang, Yeonung Jeong, Kiang HweeTan, Juhyuk Moon, "The use of limestone to replace physical filler of quartz powder in UHPFRC” Cement and Concrete Composites 94 , 2018 pp. 238-247

[24] Nancy A. Soliman, Arezki Tagnit- Hamou, ”Using glass sand as analternative for quartz sand in UHPC" Construction and Building Materials 145,2017, pp.243-252

[25] BoWei, Yimin Zhang, Shenxu Bao "Preparation of geopolymers from vanadium tailings by mechanical activation" Construction and Building Materials 145, 2017, pp 236-242

[26] MengguangZhu, Hao Wang, Li Li Liu, RuJi, Xidong Wang, "Preparation and characterization of permeable bricks from gangue and tailings" Construction and Building Materials 148 2017, pp. 484-491

[27] Diana Bajare, Girts Bumanis, Genadij Shakhmenko, Janis Justs"Obtaining composition of geopolymers (alkali activated binders) from local industrial wastes" 3 rd International conference Civil engineering`11. proceedings, building, 2011 